\title{
A Viewing Experiment on the Effects of Advertising Story
}

\author{
Yoji Kawamura \\ Faculty of Business Administration, Kindai University, \\ Address3-4-1 Kowakae \\ Higashi-osaka, Osaka 577-8502, Japan \\ E-mail:kawamura@bus.kindai.ac.jp
}

\begin{abstract}
This research lays out the conception and functions of developed Commercial Film Production Support System (CFPSS). The research then explains the results of a viewing experiment that utilized CFPSS. In this experiment where commercial films of beer were utilized, the following findings were obtained: in inducing interest, the evaluation of image type of advertising story is high; in stimulating willingness to buy, the evaluation of provider type is high; and mise-en-scène or editing attracts interest and the advertising story associated with product function and the supporting production and distribution stimulates willingness to buy. These findings gradually clarify the following creative know-how of the creator; to attract consumer interests by focusing on the stories of consumer situations in case consumers do not aware or understand their products or services; to arouse their willingness to buy by focusing on the products and stories of their acceptance and effects in case consumers have a certain level of understanding and interests in products or services.
\end{abstract}

Keywords: Commercial Film, Advertising Story, Editing, Viewing Experiment, Interest, Willingness to Buy

\section{Introduction}

There are case studies into effective commercial films with a focus on marketing and advertisement. ${ }^{1}$ Some of these studies include elements of advertising expression that have been classified and extracted to enhance advertising effects. Alternatively, other studies classifying advertising expressions according to the nature of the information (comparative, unique selling proposition, preemptive, hyperbole, generic-informatic), and the nature of transformation (user image, brand image, use occasion, generic-transformatic) examine the ideas of advertising expressions. ${ }^{2}$ However, these studies provide insight into advertising expressions from a particular vantage point, and are not conducive to developing specific rules for creating images at the microcosm level.
Related to print advertisements (text, photo, poster etc.), studies examine an interpretation and analysis of the effect of advertising rhetoric on viewers. ${ }^{3,4,5}$ However, these studies do not include analyses related to commercial films.

This paper aims to extract rules to create more specific expressions of commercial films based on a viewing experiment using CFPSS.

This experiment aims to show how an advertising story influences viewers using commercial films derived from the four types of advertising stories generated from the image shots that were likely related to the viewer's associations and experiences. 


\section{CFPSS}

Fig. 1 shows the plan of CFPSS. ${ }^{6}$ The concept of CFPSS is to generate the various commercial films adapted to the user's keywords and sentences (life scenario) input. CFPSS includes a database of 3643 image shots converted to a commercial film, that searches and classifies image shots based on keywords and sentences. The system includes a function to generate the storyboard based on the selection of advertising story, and playback in the order arranged in the storyboard. The menu of advertising story is as follows; ${ }^{7}$

- Provider story type (PT): The primary structure expresses the provider's story (production and distribution, product function, effect on company). This is the "story of the product" and "story of the company."

- Consumer story type (CT): This primary structure expresses consumers' stories (consumption situation, product acceptance, consumption effect). This is the "story of consumption."

- Overall type (OT): This structure generally expresses both the provider's and consumer's stories. This is represented as PT $+\mathrm{CT}$.

- Image type (IT): This structure expresses images related to the consumer situation, though does not express product acceptance and consumption effects in the film. Rather this structure represents a product function. This category also includes structures expressing an image that does not belong to the consumer, provider, or product function.

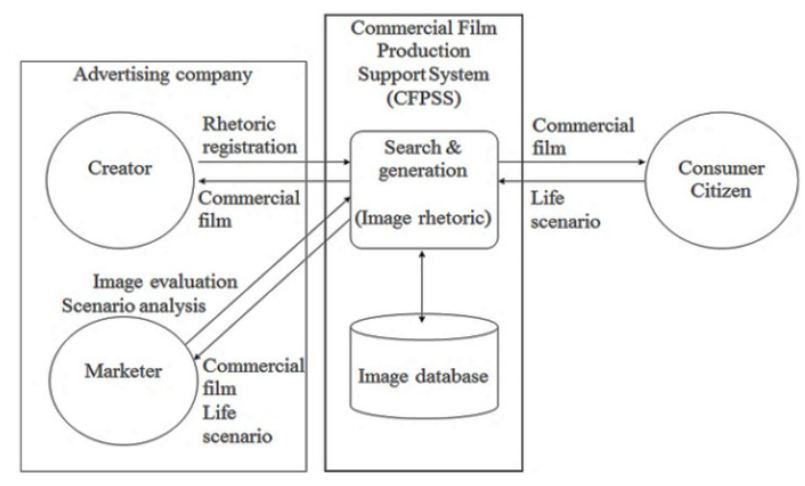

Fig. 1. CFPSS Plan.

\section{Viewing Experiment}

\subsection{Data and Method}

In this experiment, commercial films of beer were utilized. For the study, 55 viewers provided four to five associated keywords about beer and simple sentences (approximately one to two lines) about the relationship between beer and the viewer. The sample included 28 male and 27 female participants between from 20 to 23 years of age. The input from the viewers included such keywords and statements as:

- Asahi, foam, throat, bitter, mug

- A glass to drink when tired, such as after working a part-time job, is the best.

- Foam, twenty, summer, baseball, green soybeans

- The body gets itchy after drinking a beer.

- Alcohol, throat, bitter, taste, foam

The database was then searched for images using a summary of the viewers' sentences as input. An advertising story was selected from the OT, PT, CT, and IT types, and the generated image shot shown to viewers who provided their evaluations and feedback for each.

\subsection{Results}

Table 1 summarizes the image shot composition and order of the generated commercial film. The numbers in the advertising story columns indicate the order of the shots. Fig. 2 reports the viewer evaluations of interest and willingness to buy related to the four types of commercial films. IT has a greatest evaluation for interest, while PT has a greatest evaluation for willingness to buy.

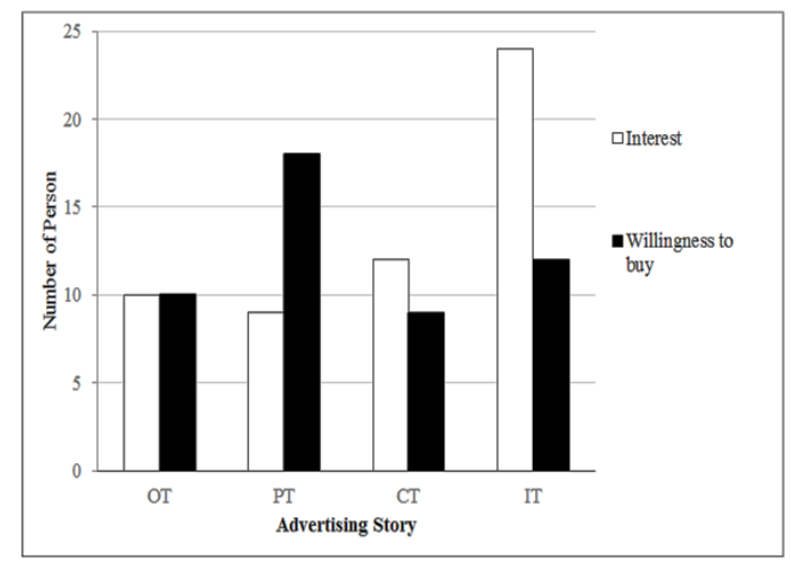

Fig. 2. Interest and willingness to buy by advertising story. 
Table 1. Image shot composition and order of the generated commercial film.

\begin{tabular}{|c|c|c|c|c|c|}
\hline \multirow{2}{*}{$\begin{array}{l}\text { Advertising } \\
\text { Phase }\end{array}$} & \multicolumn{4}{|c|}{ Advertising Story } & \multirow[t]{2}{*}{ Abstract of Shots } \\
\hline & OT & PT & CT & IT & \\
\hline \multirow{5}{*}{$\begin{array}{l}\text { Production } \\
\text { Distribution }\end{array}$} & 1 & 1 & & & Introduction of the production area of the beer \\
\hline & & 2 & & & Production process of the beer (low-temperature aging) \\
\hline & & 3 & & & Transporting the beer tank \\
\hline & 2 & 4 & & & The cook sings a song while cooking \\
\hline & & 5 & & & The products are being transported on the belt conveyor \\
\hline \multirow{8}{*}{$\begin{array}{l}\text { Consumption } \\
\text { Situation }\end{array}$} & 3 & & 1 & 1 & A lifesaver monitoring the sea \\
\hline & & & 2 & 2 & A man walking toward home \\
\hline & & & & 3 & Appear to drink a beer, even without a glass \\
\hline & & & & 4 & People talking to the camera man \\
\hline & 4 & & 3 & 5 & The consumers asked to tour the factory \\
\hline & & & & 6 & People talking at the stock exchange \\
\hline & & & & 7 & People preparing meal at the poolside \\
\hline & & & 4 & 8 & Attempting to borrow a bottle opener for beer at a seaside house \\
\hline \multirow[t]{4}{*}{ Product Function } & & 6 & & & Catch the copy of a product "All for Delight" \\
\hline & & 7 & & & Promotion of urban scenery and the product \\
\hline & 5 & 8 & 5 & 9 & Foam spilling from the beer mug \\
\hline & 6 & 9 & & 10 & Canned beer breaking the ice \\
\hline \multirow[t]{3}{*}{ Product Acceptance } & 7 & & 6 & & Consumer drinking beer in the cup \\
\hline & 8 & & 7 & & Drinking beer while socializing \\
\hline & & & 8 & & Making a toast with a large number of people \\
\hline \multirow[t]{2}{*}{ Consumption Effect } & & & 9 & & Making a mysterious face \\
\hline & 9 & & 10 & & Drinking beer and recounting funny stories \\
\hline Effect on Company & 10 & 10 & & & Urban (overseas, China) scenery \\
\hline
\end{tabular}

The summary below shows the consolidated contents for films that stimulate interest and willingness to buy for items with responses in more than two cases. The frequency of comments is indicated in parentheses.

\subsubsection{Areas of Interest}

Primarily related to the advertising story (including advertising concept):

- Copy added: “All for the customer's 'delight'!!” (4)

- Acceptance added: Demonstrations of an energetic way of drinking (2)

- Production added: When the provider's efforts to provide delicious beer is apparent (3)

Primarily related to mise-en-scène:

- Product: When the beer is widely zoomed in (2)

- Buddy added: Where there are many people are having fun (6)

- Scene added: Scene showing that the beer is actually consumed with a gesture, even in the absence of a glass (14)

Primarily related to editing:

- Connection: The plot unravels gradually (2) / There is a perceived association from the creation of a professional story extending to the consumer's consumption (2)
- Irregularity: The type of commercial message was initially unknown (2)

\subsubsection{Willingness to Buy}

Primarily related to the advertising story (including advertising concept):

- Copy added: Deceived by the phrase "All for the customer's 'delight'!!” (7)

- Situation added: A scene depicting drinking in a bar, imagining that the cuisine was easy (3) / A scene of a man going home (2)

- Acceptance added: Many scenes indicating product consumption (7)

- Effects added: The beer was consumed with zest (4)

- Production added: The story clearly shows the producer's efforts to provide delicious beer (2)

Primarily related to mise-en-scène:

- Product: The beer overflows from the cup (2) / The beer package in ice representing the chill and delight (3)

- Scene added: Drinking beer with a gesture is impressive (2) 


\subsection{Discussion}

\subsubsection{Interest and Willingness to Buy}

The IT type generated a high level of interest through a variety of image shots. However, the willingness to buy was highest for the PT type using image shots focusing on the product's function and production and distribution.

Fig. 3 summarizes the results in terms of interest and willingness to buy, or to the films' representation techniques (advertising story, mise-en-scène, editing). The results indicate that mise-en-scène and editing attracts interest, and the advertising story associated with the product function and illustrating production and distribution stimulates willingness to buy.

\subsubsection{Strategic Rules of Advertising}

From these results, it is conceivable to set the following strategic or tactical rules of advertising communications. These rules are applicable to the intelligent robot that has know-how of advertising communication between robot and human being.

- For the unfamiliar people for products, the robot stimulates the people's interest by presenting the wonder or extraordinary scene and information (for example, the environment or scene that the products are hidden consciously, the scene where there has been a lot of people etc.).

- The robot tries to grasp whether the people's interest has been evoked. If the people's interest has been aroused, the robot stimulates the willingness to buy by presenting a scene of functions, acceptance and effects of the product.

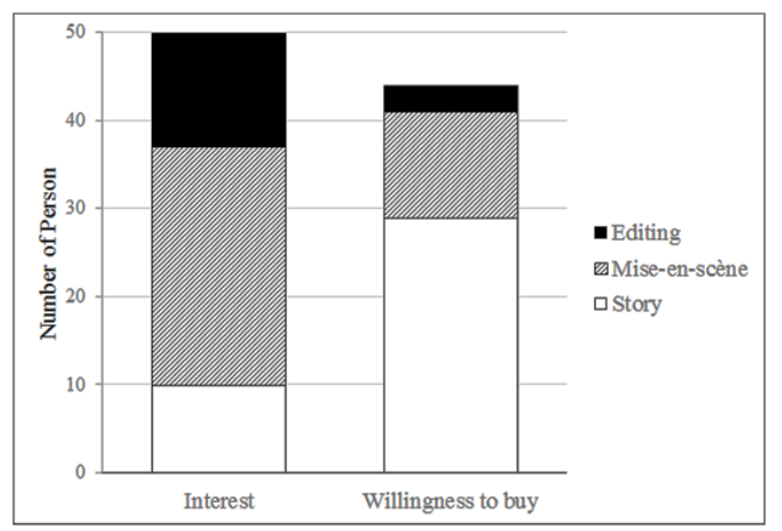

Fig. 3. Areas of interest and the willingness to buy.

\section{Conclusion}

An experiment using commercial films for beer generated the following findings:

- The IT type created the most interest through a variety of image shots.

- The PT type stimulated the highest willingness to buy using a variety of image shots showing the product function and the associated production and distribution.

- Mise-en-scène or editing attracts interest, and the advertising story associated with product function and the supporting production and distribution stimulates willingness to buy.

These findings gradually clarify the relationship between the commercial film techniques and their effects and significantly contribute to the symbolization and systematization of creator's inherent creative knowhow.

\section{Acknowledgements}

This work was supported by JSPS KAKENHI Grant Number 22500102.

\section{References}

1. D. W. Stewart and D. H. Furse, Effective television advertising: A study of 1000 commercials (Lexington Books, Lexington, MA, 1986).

2. H. A. Laskey, E. Day and M. R. Crask, Typology of main message strategies for television commercial, $J$. Advertising 18(1) (1989) 36-41.

3. E. F. McQuarrie and D. G. Mick, Figures of rhetoric in advertising language, J. Consumer Research 22(4) (1996) 424-438.

4. B. A. Huhmann and P. A. Albinsson, Does rhetoric impact advertising effectiveness with liking controlled?, European J. Marketing 46(11/12) (2012) 1476-1500.

5. I. G. Theodorakis, C. Koritos and V. Stathakopoulos, Rhetorical maneuvers in a controversial tide: assessing the boundaries of advertising rhetoric, J. Advertising 44(1) (2015) 14-24.

6. Y. Kawamura, An analysis of the rhetoric of commercial film -toward the building of a commercial film production support system based on image rhetoric, in Proc. 2003 IEEE Int. Conf. Systems, Man and Cybernetics , (Washington, DC., 2003), pp.993-1000.

7. Y. Kawamura, An analysis on the story and editing techniques of commercial film -toward the building of a commercial film production support information system, J. Advertising Science 50 (2009) 16-32. (In Japanese). 